Check for updates

Cite this: J. Mater. Chem. A, 2020, 8 , 11414

Received 6th January 2020

Accepted 12th May 2020

DOI: $10.1039 / d 0 t a 00216 j$

rsc.li/materials-a

\title{
Fatigue resistant lead-free multilayer ceramic capacitors with ultrahigh energy density $\dagger$
}

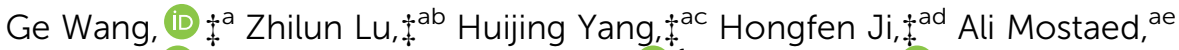 \\ Linhao Li, (D) a Yiqi Wei, ${ }^{a}$ Antonio Feteira, (D) ${ }^{f}$ Shikuan Sun, (D) a Derek C. Sinclair, (DD a \\ Dawei Wang ${ }^{\star a}$ and Ian M. Reaney ${ }^{a}$
}

\begin{abstract}
The critical role of electrical homogeneity in optimising electric-field breakdown strength (BDS) and energy storage in high energy density $(0.7-x) \mathrm{BiFeO}_{3}-0.3 \mathrm{BaTiO}_{3}-x \mathrm{Bi}\left(\mathrm{Li}_{0.5} \mathrm{Nb}_{0.5}\right) \mathrm{O}_{3}(\mathrm{BF}-\mathrm{BT}-x \mathrm{BLN})$ lead-free capacitors is demonstrated. The high BDS for bulk ceramics and multilayers (dielectric layer thickness $8 \mu \mathrm{m}$ ) of $\sim 260$ and $\sim 950 \mathrm{kV} \mathrm{cm}^{-1}$, respectively, gives rise to record-performance of recoverable energy density, $W_{\text {rec }}=13.8 \mathrm{~J} \mathrm{~cm}^{-3}$ and efficiency, $\eta=81 \%$. Under an electric field of $400 \mathrm{kV} \mathrm{cm}^{-1}$, multilayers are temperature stable up to $100^{\circ} \mathrm{C}$, frequency independent in the range $10^{-2}$ to $10^{2} \mathrm{~Hz}$, have low strain $(<0.03 \%)$ and are fatigue-resistant up to $10^{4}$ cycles $\left(W_{\text {rec }}\right.$ variation $\left.<10 \%\right)$. These properties show promise for practical use in pulsed power systems.
\end{abstract}

\section{Introduction}

The depletion of fossil fuel reserves and serious concerns over climate change have provoked the development of renewable energy including tidal, wind and solar. ${ }^{1-5}$ Electrical energy is currently stored or generated autonomously through a range of devices such as fuel cells and batteries..$^{1-3,6-13}$ For energy storage applications, dielectric capacitors have the advantages of fast charging-discharging speed, superior temperature stability and are mainly used for pulsed power applications such as power distribution, medical transportation devices and pulsed power weapons. ${ }^{4,5,14-18}$ Dielectric polymers are limited by their low melting temperatures and related degradation. ${ }^{1,2}$ Dielectric ceramics are potentially more temperature stable than dielectric polymers but have comparatively low recoverable energy density $\left(W_{\text {rec }}\right)$ and energy conversion efficiency $(\eta)$, due to their low electric-field breakdown strength (BDS) and high energy loss ( $\left.W_{\text {loss }}\right)$.

${ }^{a}$ Department of Materials Science and Engineering, University of Sheffield, Sheffield, S1 3JD, UK. E-mail: dawei.wang@sheffield.ac.uk

${ }^{b}$ The Henry Royce Institute, Sir Robert Hadfield Building, Sheffield, S1 3JD, UK 'Department of Physics, Tangshan Normal University, Tangshan 063000, China ${ }^{d}$ Laboratory of Thin Film Techniques and Optical Test, Xi'an Technological University, Xi'an 710032, China

${ }^{e}$ Department of Materials, University of Oxford, Parks Road, Oxford OX1 3PH, UK ${ }^{f}$ Christian Doppler Laboratory for Advanced Ferroic Oxides, Sheffield Hallam University, Sheffield, S1 1WB, UK

$\dagger$ Electronic supplementary information (ESI) available. See DOI: 10.1039/d0ta00216j

\$ G. W., Z. L. H. Y. and H. J. contributed equally to this work and should be considered as co-first authors.
To satisfy the requirements of power supply components in portable electronics, electric vehicles and other high power and energy storage applications, both high $W_{\text {rec }}$ and $\eta$ are required. For dielectric capacitors, the total energy density $(W), W_{\text {rec }}$ and $\eta$ are given by:

$$
\begin{gathered}
W=\int_{0}^{P_{\max }} E \mathrm{~d} P, \\
W_{\mathrm{rec}}=\int_{P_{\mathrm{r}}}^{P_{\max }} E \mathrm{~d} P, \\
\eta=W_{\mathrm{rec}} / W
\end{gathered}
$$

where $P, P_{\max }$ and $P_{\mathrm{r}}$ are the polarization, maximum polarization and remnant polarisation, respectively. A high BDS, combined with large $P_{\max }$ and small $P_{\mathrm{r}}$ are simultaneously desirable to achieve both high $W_{\text {rec }}$ and $\eta$. Furthermore, the stability and fatigue resistance of materials and devices over a range of temperature and frequency are equally critical. ${ }^{19-22}$

Although high energy storage performance with $W_{\text {rec }} \sim 10.4 \mathrm{~J}$ $\mathrm{cm}^{-3}$ and a $\eta \sim 87 \%$ has been achieved with La and Sn co-doped lead zirconate at $400 \mathrm{kV} \mathrm{cm}^{-1}$, ${ }^{23}$ lead-free ceramics based on $\mathrm{AgNbO}_{3}(\mathrm{AN}), \mathrm{BaTiO}_{3}(\mathrm{BT}),\left(\mathrm{Bi}_{0.5} \mathrm{Na}_{0.5}\right) \mathrm{TiO}_{3}(\mathrm{BNT}),\left(\mathrm{K}_{0.5} \mathrm{Na}_{0.5}\right) \mathrm{NbO}_{3}$ $(\mathrm{KNN})$ and $\mathrm{BiFeO}_{3}-\mathrm{BaTiO}_{3}(\mathrm{BF}-\mathrm{BT})$ have all been studied due to concerns over the toxicity of lead. ${ }^{24-56} \mathrm{High} W_{\text {rec }}\left(>3 \mathrm{~J} \mathrm{~cm}^{-3}\right)$ has been reported in antiferroelectric (AFE) (Ta, La and Gd)-doped AN with enhanced BDS up to $300 \mathrm{kV} \mathrm{cm}{ }^{-1} \cdot{ }^{24-28}$ Oxide additives $\left(\mathrm{Al}_{2} \mathrm{O}_{3}\right.$, $\left.\mathrm{SiO}_{2}, \mathrm{MgO}\right)$ and $\mathrm{Bi}(\mathrm{A}, \mathrm{B}) \mathrm{O}_{3}(\mathrm{~A}=\mathrm{Li}, \mathrm{Mg}$ and $\mathrm{Zn}, \mathrm{B}=\mathrm{Nb}, \mathrm{Ta}$, Ti and $\mathrm{Zr}$ ) have all been found to improve $W_{\text {rec }}$ and BDS of BT-based ceramics up to $2.9 \mathrm{~J} \mathrm{~cm}^{-3}$ and $300 \mathrm{kV} \mathrm{cm}^{-1}$, respectively. ${ }^{29-36}$ Recently, $W_{\text {rec }} \sim 7 \mathrm{~J} \mathrm{~cm}^{-3}$ with high $\eta \sim 85 \%$ was reported in $\mathrm{NaNbO}_{3}$-doped $\mathrm{BNT}^{37}$ at $390 \mathrm{kV} \mathrm{cm}^{-1}$ and $W_{\text {rec }} \sim 4 \mathrm{~J} \mathrm{~cm}^{-3}$ were 
also obtained for KNN-based ceramics due to enhancement of BDS (300-400 kV cm ${ }^{-1}$ ) by controlled grain growth. ${ }^{46-49}$

$(1-x) \mathrm{BF}-x \mathrm{BT}$ materials initially drew attention as potential lead-free piezoelectrics with high piezoelectric coefficient $\left(d_{33}\right)$ $\sim 402 \mathrm{pC} \mathrm{N}^{-1}$, normalised strain $\left(d_{33}^{*}\right) \sim 600 \mathrm{pm} \mathrm{V}^{-1}$ and Curie temperature $\left(T_{\mathrm{c}}\right) \sim 454{ }^{\circ} \mathrm{C}$ in a mixed-phase region of rhombohedral and pseudocubic with $x=0.25$ to $0.35 .{ }^{57,58}$ The mixture of highly polarisable ions such as $\mathrm{Bi}^{3+}$ and $\mathrm{Ti}^{4+}$ in a matrix of dissimilar sized $\mathrm{ABO}_{3}$, perovskite unit cells is considered responsible for its strong piezoelectric/electrostrictive response. ${ }^{59}$ These crystallo-chemical features are also considered ideal for optimising polarisation within a pseudocubic relaxor phase and thus provide a base from which to devise materials with high energy density. For example, BF-BT based compositions with various dopants such as $\mathrm{Nd}$ and $\mathrm{A}\left(\mathrm{B}_{1}, \mathrm{~B}_{2}\right) \mathrm{O}_{3}$ $\left(\mathrm{A}=\mathrm{Bi}\right.$ and $\mathrm{Nd}, \mathrm{B}_{1}=\mathrm{Zn}$ and $\mathrm{Mg}, \mathrm{B}_{2}=\mathrm{Nb}$ and $\left.\mathrm{Zr}\right),{ }^{50-56}$ have all been shown to exhibit high energy density. The best compositions to date however, are doped with $\mathrm{Nd}\left(\mathrm{Zn}_{1 / 2} \mathrm{Zr}_{1 / 2}\right) \mathrm{O}_{3}$ and give $W_{\text {rec }} \sim 2.5 \mathrm{~J} \mathrm{~cm}^{-3}$ with BDS $>260 \mathrm{kV} \mathrm{cm}^{-1}$ for ceramics which improve dramatically when multilayered to $10.5 \mathrm{~J} \mathrm{~cm}^{-3}$ at 700 $\mathrm{kV} \mathrm{cm}{ }^{-1} \cdot{ }^{56}$

Enhancement of BDS in dielectric materials is an effective approach to optimize $W_{\text {rec }}$, and is associated with factors such as the band gap, reduced porosity, grain size, impurity concentrations, sample thickness/geometry and spacecharging polarization. ${ }^{60}$ However, practically, BDS is limited in many materials by the presence of conductive pathways, e.g. from core to core or from shell to shell, which appear as electrical inhomogeneity in impedance spectroscopy (IS) data. ${ }^{61-63}$

The relationship between BDS and dielectric layer thickness was first published by Gerson and Marshall in $1959 .{ }^{64}$ In principle, all solid dielectrics increase their BDS with decreasing layer thickness, culminating in values of $>1 \mathrm{mV} \mathrm{cm}^{-1}$ for thin films. ${ }^{65}$ In our own research, we have demonstrated this effect numerous times, as have several research groups, by fabricating multilayer capacitors $(10 \mu \mathrm{m}$ dielectric layer thickness) once good properties (high resistivity and electrical homogeneity) have been demonstrated in bulk ceramics. ${ }^{51,56}$ However, with any given multilayer, short circuit pathways can emerge between low resistivity regions as layer thickness decreases, thereby decreasing BDS. The caveat therefore, which must be applied to the Gerson and Marshall ${ }^{64}$ relationship is that BDS will only increase if low resistivity pathways are eliminated, i.e. the materials have high resistivity and are electrically homogeneous.

In this study, we utilise stoichiometric doping, the nature of which is complex but which has been dealt with by Sinclair and co-workers for several systems, e.g. BNT-based, ${ }^{66-68}$ and BF-BTbased $^{69-71}$ materials. Stoichiometric doping has been shown to be effective at reducing conductivity and promoting electrical homogeneity in a wide range of systems. ${ }^{50,56,67,68}$ By eliminating extrinsic effects through electrical homogeneity, we enable the Gerson and Marshall effect (Fig. 1), resulting in $W_{\text {rec }} \sim 13.8 \mathrm{~J}$ $\mathrm{cm}^{-3}$ at $\sim 950 \mathrm{kV} \mathrm{cm}{ }^{-1}$ in $0.57 \mathrm{BiFeO}_{3}-0.30 \mathrm{BaTiO}_{3}-0.13 \mathrm{Bi}\left(\mathrm{Li}_{0.5^{-}}\right.$ $\left.\mathrm{Nb}_{0.5}\right) \mathrm{O}_{3}$ (BF-BT-0.13BLN) ceramic multilayers. Furthermore, excellent fatigue properties with respect to temperature,

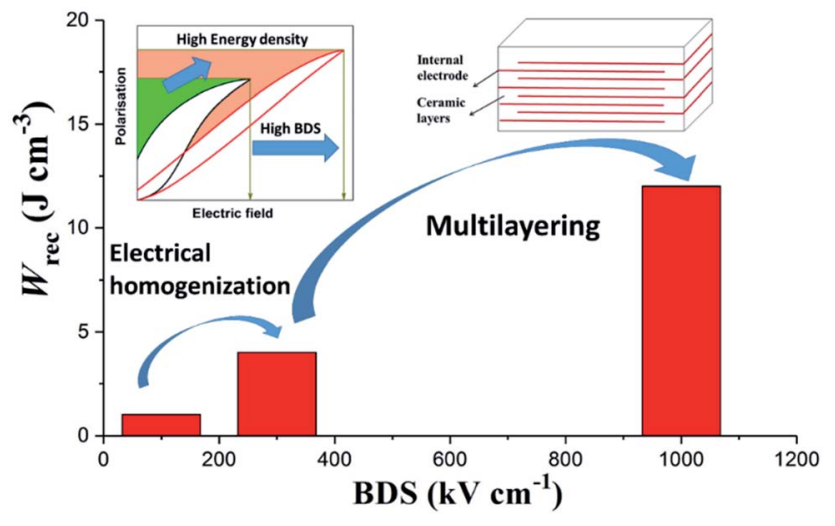

Fig. 1 Schematic representation of the approach for optimisation of $\mathrm{BDS}$ and $W_{\text {rec }}$ by electrical homogenization and multilayering.

frequency and cyclic poling are demonstrated, which play a critical role in practical applications.

\section{Results and discussion}

\section{High energy density dielectric ceramics}

The crystal structure of crushed BF-BT- $x$ BLN ceramics $(0.00 \leq x$ $\leq 0.15)$ was determined using X-ray powder diffraction (XRD), as shown in Fig. 2a. XRD patterns are indexed as a single-phase perovskite phase without any detectable secondary impurity phases for $x<0.08$. Impurity peaks are observed for $x \geq 0.08$ at which point in the composition, the solid solubility limit of $\mathrm{Li}_{0.5} \mathrm{Nb}_{0.5}$ on the B-site of BF-BT is exceeded. The average ionic radii $(R)$ of $\left(\mathrm{Li}_{0.5} \mathrm{Nb}_{0.5}\right)^{3+}$ ions are given by $R=0.5 R\left(\mathrm{Li}^{+}\right)+$ $0.5 R\left(\mathrm{Nb}^{5+}\right)=0.70 \AA(0.76 \AA$ and $0.64 \AA$ are the respective ionic radii of $\mathrm{Li}^{+}$and $\mathrm{Nb}^{5+}$ in six-fold coordination), which is larger than that of $\mathrm{Fe}^{3+}$ and $\mathrm{Ti}^{4+}(0.645$ and $0.605 \AA$, respectively) in the same co-ordination. ${ }^{72}$ As $x$ increases therefore, diffraction peaks shift left, commensurate with an increase in lattice parameter (Fig. S1, ESI $\dagger$ ). A full-pattern Rietveld refinement on XRD data for BF-BT-0.13BLN ceramics has been conducted using TOPAS 5. The best fitting was obtained using a mixed-phase assemblage of $R 3 c$ rhombohedral (14\%) and $P m \overline{3} m$ cubic phase (86\%), as displayed in Fig. S2 and Table S1 (ESI $\dagger$ ), consistent with previous reports on BF-BT ternary systems. ${ }^{.0051,56,73,76}$

The temperature-dependent permittivity $\left(\begin{array}{lll}\varepsilon_{\mathrm{r}} & v s . & T\end{array}\right)$ and dielectric loss $(\tan \delta$ vs. T) data at $100 \mathrm{kHz}$ for BF-BT- $x \mathrm{BLN}$ ceramics are presented in Fig. 2b. A single sharp peak at a $T_{\mathrm{c}}$ of $\sim 480{ }^{\circ} \mathrm{C}$ is observed for undoped BF-BT, associated with a ferroelectric to paraelectric transition. As the BLN concentration increasing, the dielectric maxima broadens, accompanied by a lowering of the maximum value of $\varepsilon_{\mathrm{r}}$. Broad frequencydependent $\varepsilon_{\mathrm{r}}-T$ peaks are obtained for compositions with $x>$ 0.02 , as displayed in Fig. S3 (ESI $\dagger$ ), indicating a compositionally driven transition from dominantly ferroelectric to relaxor behaviour. Despite these changes, low values of $\tan \delta$ are recorded in all samples below $250^{\circ} \mathrm{C}$ but increase substantially above this temperature. There is however, no systematic trend in the dielectric loss above $250{ }^{\circ} \mathrm{C}$ with increasing $x$. There will be increasing contributions from space charge (long range 
(a)

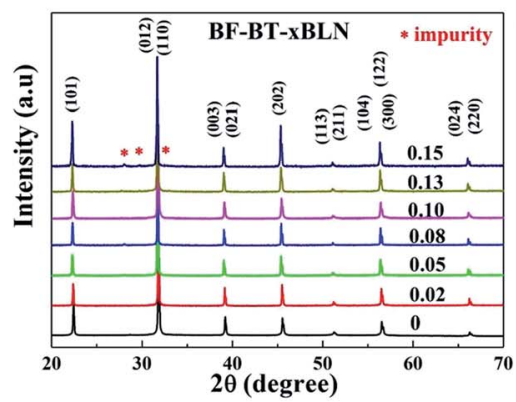

(c)

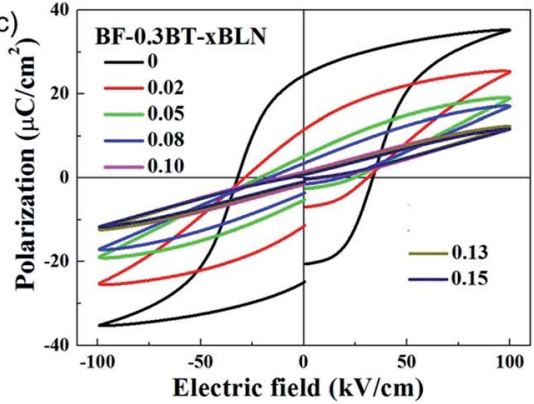

(b)

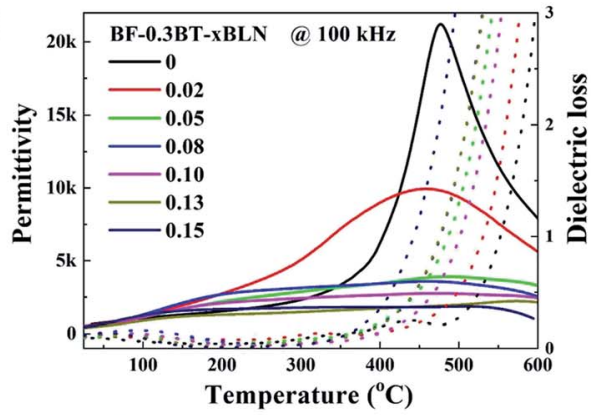

(d)
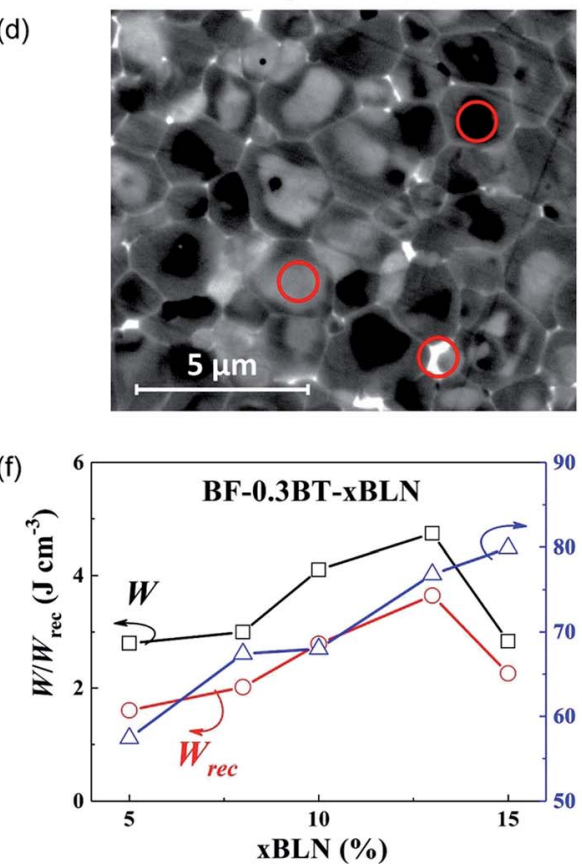

Fig. 2 (a) XRD patterns for BF-BT-xBLN ( $x=0.00-0.15)$. (b) Temperature-dependent permittivity and dielectric loss data for BF-BT- $x \mathrm{BLN}$ ceramics at a frequency of $100 \mathrm{kHz}$. (c) Bipolar P-E loops for BF-BT-xBLN ceramics (d) EDS elemental spot analysis (circled) for BF-BT-0.13BLN ceramics. (e) Unipolar P-E loops under $E_{\max }$ and (f) energy storage properties under $E_{\max }$ for $\mathrm{BF}-\mathrm{BT}-x \mathrm{BLN}$ ceramics.

conduction) to the loss but bulk conductivity values obtained from impedance spectroscopy data do not support a simple hypothesis of increasing oxygen vacancies with BLN content, as illustrated in Fig. S4 (ESI $\dagger$ ). In fact, the bulk conductivity is lower in $x=0.15$ than it is for lower $x$ values.

The activation energy for total conductivity (Fig. S4, ESI $\dagger$ ) remains broadly the same for all compositions suggesting the conduction mechanism (but not necessarily) remains the same as dopant concentration increases. Conductivity remains via $V_{O}$ diffusion throughout consistent with an activation energy of 1.1-1.2 $\mathrm{eV}$ and points to substitution/compensation in accordance with the batched stoichiometry. ${ }^{67}$ However, the site location of Li may locally play a role in the defect chemistry and is an area of future work.

From Fig. $2 \mathrm{~b}, x=0$ shows classic paraelectric behaviour above $T_{\mathrm{c}}$ at $480{ }^{\circ} \mathrm{C}$ whereas with increasing $x, \varepsilon_{\mathrm{r}}$ in the range $480-600{ }^{\circ} \mathrm{C}$ broadens and becomes relaxor-like. As a consequence, a significant contribution to the loss must still be associated with polarisation rotation/coalescence of polar nano regions (relaxor behaviour) at higher values of $x$. Polarization-electric field (P-E) loops obtained at $100 \mathrm{kV} \mathrm{cm}^{-1}$ for BF-BT- $x$ BLN ceramics are displayed in Fig. $2 \mathrm{c}$. The highest polarization values are recorded for undoped BF-BT with $P_{\max }$ $\sim 34 \mu \mathrm{C} \mathrm{cm}^{-2}$ and $P_{\mathrm{r}} \sim 25 \mu \mathrm{C} \mathrm{cm}^{-2}$. P-E loops become slimmer and are no longer saturated as increasing BLN concentration, along with a continuous reduction of $P_{\max }, P_{\mathrm{r}}$ and $E_{\mathrm{C}}$ (Fig. S5, ESI $\uparrow$ ), typical of a transition from ferroelectric to relaxor behaviour.

The scanning and backscattered electron microscopy (SEM and BSE) images for BF-BT- $x$ BLN ceramics are displayed in Fig. S6 and S7 (ESI $\uparrow)$. The largest grain size $(\sim 8 \mu \mathrm{m})$ is observed for undoped BF-BT. For BLN-doped compositions, the grain size reduces significantly (Fig. S6 and S7, ESI $†$ ) accompanied by the formation of a core-shell microstructure, exhibiting $\mathrm{Bi} / \mathrm{Fe}-$ rich (bright), Ba-rich (dark) regions and Bi-rich (bright GB phase) via energy dispersive X-ray spectroscopy (EDS) analysis, Fig. 2d and Table S2 (ESI $\dagger$ ). The bright grain boundary phase is Bi-rich, consistent with impurity peaks in XRD pattern.

The formation of the core-shell structure is driven by immiscibilty of the perovskite end members which not only have dissimilar ion size, e.g. $\mathrm{Ba}^{2+}>>\mathrm{Bi}^{3+}$ but have different bonding with $\mathrm{Bi}^{3+}$ being dominantly covalent whereas $\mathrm{Ba}^{2+}$ is 
considered ionic. Immiscibility in part can be suppressed by quenching and by careful selection of dopants. ${ }^{70,71,74-76}$ The core-shell structure in BF-BT-0.13BLN ceramics was investigated further by transmission electron microscopy (TEM) (Fig. S8, ESI $\dagger$ ) and exhibits small tweed domains (core) and a shell of nanodomains, similar to previous reports in BF-BTbased ceramics. ${ }^{51,56,74-76}$

The grain size for BF-BT- $x$ BLN ceramics decreases from $\sim 8.2 \pm 0.5 \mu \mathrm{m}$ for $x=0.00$ to $1.1 \pm 0.2 \mu \mathrm{m}$ for $x=0.05$ and then increases slightly to $2.0 \pm 0.2 \mu \mathrm{m}$ for $x=0.15$. The grain size for the optimized composition, BF-BT-0.13BLN, is $1.5 \pm 0.2 \mu \mathrm{m}$. The major change in grain size therefore, occurs between $0<x<$ 0.05. A sudden decrease in grain size with dopants is common in solid solutions and may be attributed to an increase of grain boundary drag, related to the incorporation of a high valence species such as Nb. ${ }^{47,48,77,78}$ The similar grain size for all subsequent compositions for $x>0.05$ indicates that it is not a critical factor in optimising the energy density in ceramics as $x$ increases. However, for multilayers with $\sim 8 \mu$ m layer thickness the decrease from $\sim 8$ to $\sim 1-2 \mu \mathrm{m}$ is important as it ensures there are multiple grains rather than a single grain separating the electrodes and thereby eliminating the potential of short circuit conduction pathways and maintaining a high BDS.

Energy storage properties are obtained using unipolar P-E loops up to the maximum electric field $\left(E_{\max }\right)$. Due to low BDS $\left(<120 \mathrm{kV} \mathrm{cm}^{-1}\right)$ and high energy loss, compositions with $x \leq$ 0.02 (Fig. 2c) are not considered desirable for energy storage applications. Compositions with $0.05 \leq x \leq 0.15$ with a strong core-shell contrast exhibits greater potential for energy storage and are considered for further characterization. The unipolar P-E loops of BF-BT- $x$ BLN $(0.05 \leq x \leq 0.15)$ under $E_{\max }$ are displayed in Fig. 2e and S9 (ESI†), with corresponding values of
$P_{\max }, P_{r}, \Delta P$ and $E_{\max }$ given in Fig. S10 (ESI $\dagger$ ). With increasing electric field, $P_{\max }$, and $\Delta P$ increase linearly with a slight improvement of $P_{\mathrm{r}}$ (Fig. S10a-e, ESI $\dagger$ ). $\Delta P$ and $E_{\max }$ increase initially and then decrease after reaching a maximum of $\Delta P \sim$ $32.5 \mu \mathrm{C} \mathrm{cm}^{-2}$ for $x=0.10$ and $E_{\max } \sim 260 \mathrm{kV} \mathrm{cm}^{-1}$ for $x=0.13$, respectively (Fig. S10f, ESI $\dagger$ ). $W, W_{\text {rec }}$ and $\eta$ at different electric fields are calculated according to eqn (1)-(3) and presented in Fig. S11 (ESI $\dagger$ ). At $E_{\max }$, the highest $W\left(4.74 \mathrm{~J} \mathrm{~cm}^{-3}\right)$ and $W_{\text {rec }}$ (3.64 $\left.\mathrm{J} \mathrm{cm}^{-3}\right)$ are obtained for $x=0.13$ ceramics, while the highest $\eta(\sim 80 \%)$ is attained for $x=0.15$ ceramics, as illustrated in Fig. $2 \mathrm{f}$.

The electrical microstructure of BF-BT- $x$ BLN ceramics is investigated by impedance spectroscopy (IS) as a function of temperature and frequency. The spectroscopic plots of $\mathrm{Z}^{\prime \prime}$ and $\mathrm{M}^{\prime \prime}$ at $250{ }^{\circ} \mathrm{C}$ for BF-BT- $x$ BLN with $x=0.00$ and $x=0.13$ are shown in Fig. 3. For undoped BF-BT, two electrical components are observed in the $\mathrm{M}^{\prime \prime}$ spectra with capacitances $(C)$ of $\sim 6.83 \times 10^{-10}$ and $1.24 \times 10^{-9} \mathrm{~F} \mathrm{~cm}^{-1}$, at $80 \mathrm{~Hz}$ and $10 \mathrm{kHz}$ (Fig. 3a), respectively. These peaks are temperature dependent, both decrease in height (and therefore increased in capacitance, as shown in Fig. S4, ESI $\dagger$ ) with increasing temperature in the range $\sim 250-400{ }^{\circ} \mathrm{C}$. This is consistent with the $\varepsilon_{\mathrm{r}}-T$ data in this range, Fig. 2a, and indicates both elements are consistent with ferroelectric-type regions below $T_{\mathrm{c}}$. The $C$ values obtained from the $\mathrm{M}^{\prime \prime}$ peaks in the spectra are consistent with bulk-type responses for these polar ceramics and the large separation in their maximum frequency $\left(f_{\max }\right)$ values indicate components with a large difference in resistance $(R)$, therefore suggesting the grains are electrically inhomogeneous. Equivalent circuit-fitting (to a first approximation) to a model based on two parallel resistor-capacitor (RC) elements connected in series gave plausible temperature-
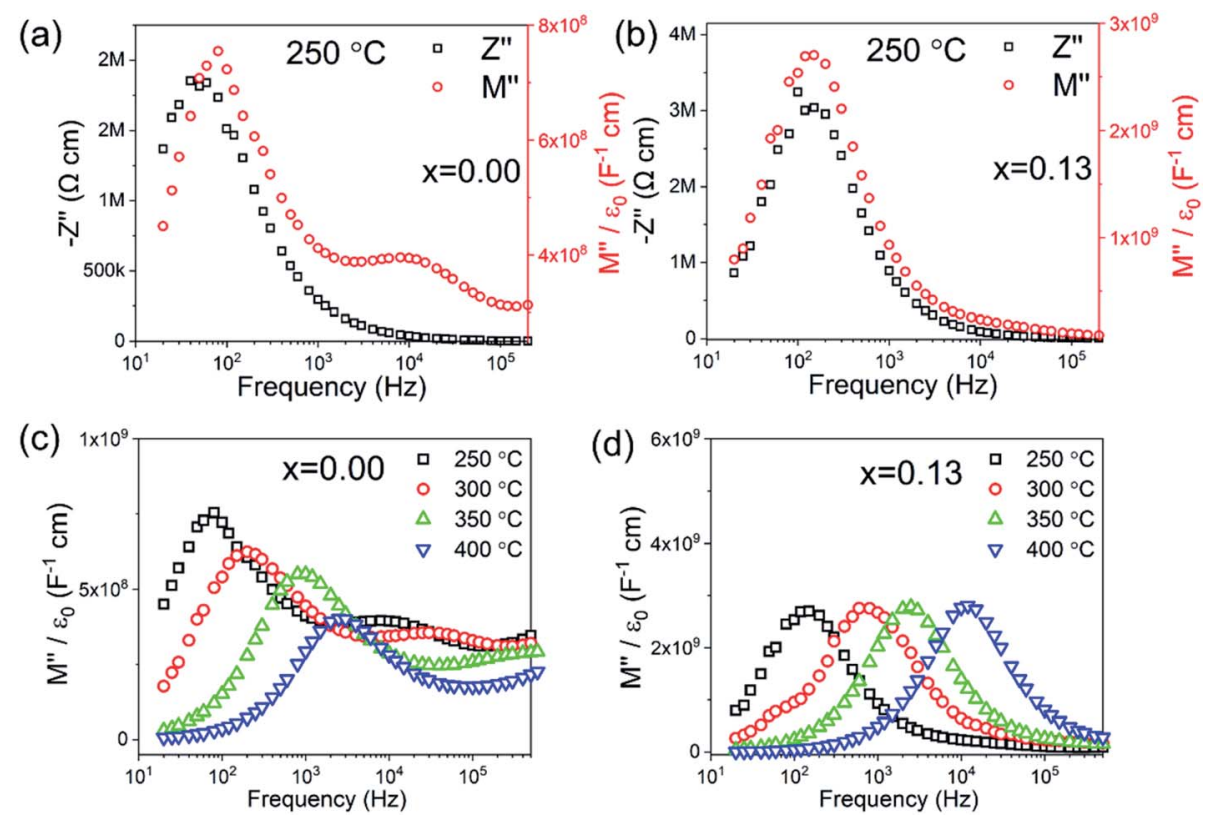

Fig. 3 Combined $Z^{\prime \prime}$ and $M^{\prime \prime}$ spectroscopic plots at $250{ }^{\circ} \mathrm{C}$ of BT-0.3BT-xBLN for $x=$ (a) 0.00 and (b) 0.13 ; temperature-dependent $\mathrm{M}^{\prime \prime}$ spectroscopic plots for $x=$ (c) 0.00 and (d) 0.13 . 
dependent permittivity and conductivity values (see ESI, Fig. S4 and S12, $\dagger$ respectively) that are consistent with a conductive-core and resistive-shell type electrical microstructure. A resistivity of $\sim 1.9 \mathrm{M} \Omega \mathrm{cm}$ is obtained from the $Z^{\prime \prime}-f$ spectroscopic plot for the lower frequency (shell) component at $\sim 80 \mathrm{~Hz}$ which dominates the $Z^{\prime \prime}-f$ spectrum; an accurate estimate for the resistivity of the higher frequency (core) component cannot be obtained from the $Z^{\prime \prime}-f$ spectrum but is calculated to be $\sim 1.3 \mathrm{k} \Omega \mathrm{cm}$ using the relationship $\omega \mathrm{RC}=1$ (where $\omega=2 \pi f$, with $f$ in $\mathrm{Hz}$ ) from the second, higher frequency $\mathbf{M}^{\prime \prime}$ peak at $10 \mathrm{kHz}^{.56,62}$ With increasing BLN concentration, the higher frequency $\mathbf{M}^{\prime \prime}$ peak associated with the core-type response remains clearly visible for $x<0.08$; however, for $0.08 \leq x \leq 0.15$ its presence has visibly decreased and is absent for $x \geq 0.13$, Fig. S13 and S14 (ESI $\dagger$ ). The large $Z^{\prime \prime}$ spectroscopic peak remains at $\sim 100 \mathrm{~Hz}$ with increasing BLN content, however its magnitude increases from $\sim 2$ to $3 \mathrm{M} \Omega \mathrm{cm}$, Fig. S13 (ESI $\dagger$ ).

Only a single peak is observed in the spectroscopic plots of $\mathrm{Z}^{\prime \prime}$ and $\mathrm{M}^{\prime \prime}$ at $250{ }^{\circ} \mathrm{C}$ for $x=0.13$ (Fig. 3b), corresponding to a single bulk component with $\mathrm{C} \sim 1.68 \times 10^{-10} \mathrm{~F} \mathrm{~cm}^{-1}$ (from the $\mathrm{M}^{\prime \prime}$ peak) and resistivity, $R$ of $\sim 6 \mathrm{M} \Omega \mathrm{cm}$ (from the $\mathrm{Z}^{\prime \prime}$ peak).

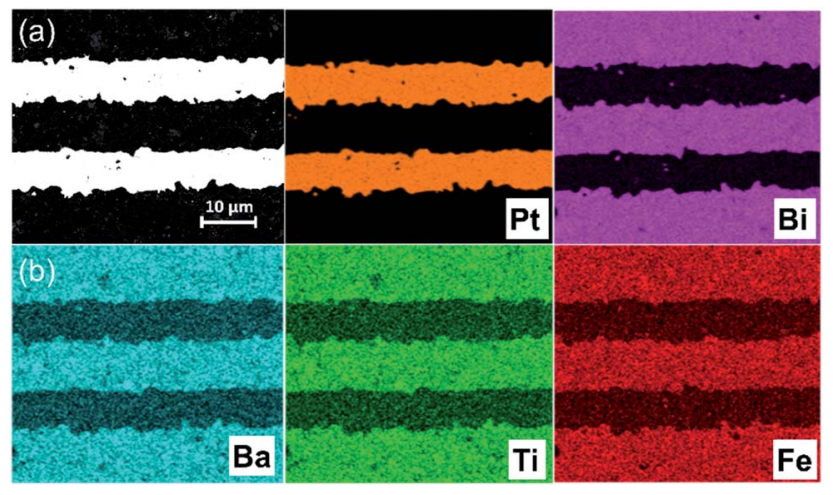

Fig. 4 (a) BSE cross section micrographs of BF-BT-0.13BLN multilayer MLCCS; (b) EDS mapping of each elemental metal distribution.
It is noteworthy that the $\mathbf{M}^{\prime \prime}$ peak height is largely invariant in the temperature range $\sim 250-400{ }^{\circ} \mathrm{C}$ (Fig. 3d) which is consistent with the flat $\varepsilon_{\mathrm{r}}-T$ response observed from fixed frequency dielectric measurements in Fig. 2b. Temperaturedependent spectroscopic plots of $\mathrm{M}^{\prime \prime}$ for $x=0.00$ and $x=$ 0.13 are displayed in Fig. $3 c$ and $d$. The high-frequency conductive component observed for $x=0.00$ can only be observed below $350{ }^{\circ} \mathrm{C}$ due to its time constant (RC product) exceeding the upper frequency range measured in our experiments. The magnitude and temperature dependence of $\mathrm{C}$ values from the $\mathbf{M}^{\prime \prime}$ peaks confirm the predominantly ferroelectric nature of core and shell components in $x=0$ and overall relaxor-ferroelectric behaviour in the electrically homogeneous grains of $x=0.13$. The IS data indicates that short circuit conduction paths are more likely to form under high field for $x<0.08$ via the conductive grain cores, however, for $x>0.08$, enhanced BDS as well as $W_{\text {rec }}$ can be achieved due to improved electrical homogeneity with a much lower volume fraction of conductive cores.

\section{Multilayer ceramic capacitors (MLCCs)}

To increase the BDS and energy storage properties, multilayer ceramic capacitors of BF-BT-0.13BLN were fabricated with $\sim 8$ $\mu \mathrm{m}$ thick dielectric layers with active electrode area of $5 \mathrm{~mm}^{2}$, as presented in Fig. $4 \mathrm{a}$ and $\mathrm{b}$.

Fig. 5a shows a TEM image obtained from the interface between the BF-BT-0.13BLN ceramic and Pt electrode. According to the selected area electron diffraction (SAED) patterns in Fig. 5b and (c), the $\{001\}$ atomic planes of the ceramic grain displayed in Fig. 5 a are $\sim 4^{\circ}$ off parallel to $\mathrm{Pt}$ $\{115\}$ but we do not suggest that this is due an epitaxial relation as the multilayers are formed by a powder-based tape-cast process. Consistent with XRD results, the SAED patterns displayed in Fig. 5b and S15 (ESI $\dagger$ ) obtained from the BF-BT-13BLN ceramic along [210] and [100] zone axes, respectively, indicating they are perovskite structured. An amorphous layer $(\sim 4 \mathrm{~nm})$ is observed at the interface between
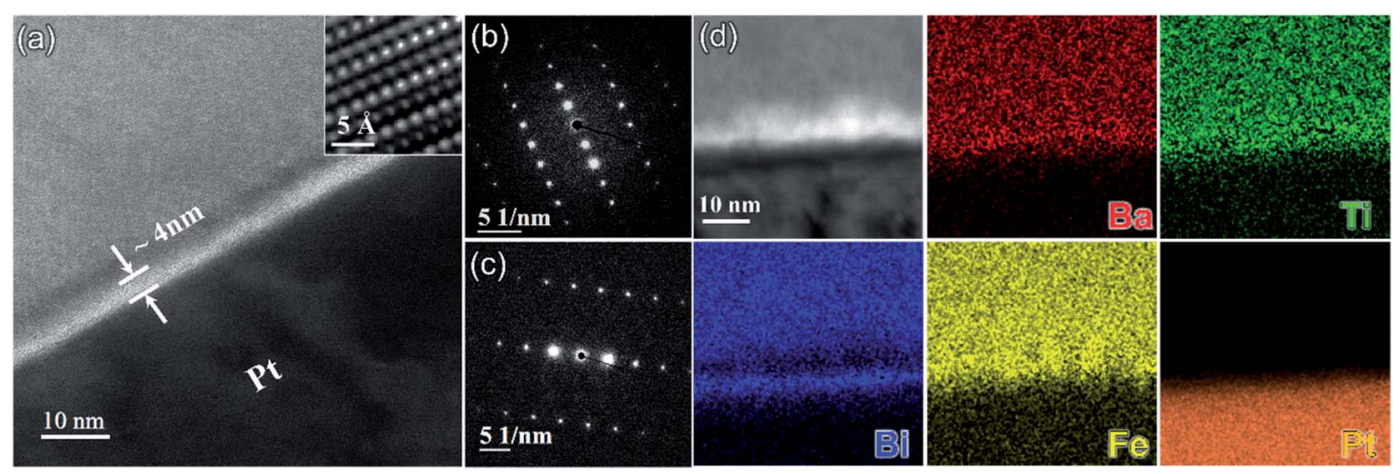

Fig. 5 (a) TEM micrograph obtained from an interface between a BF-BT-0.13BLN grain and a Pt grain (electrode). Here the Pt grain is close to its [321] zone axis and the BF-BT-0.13BLN grain is $\sim 4^{\circ}$ off from its [210] zone axis; inset shows an high resolution transmission electron microscopy (HRTEM) image (filtered) obtained from the BF-BT-0.13BLN grain at a higher magnification. (b) <210> SAED pattern obtained from the BF-BT$0.13 B L N$ grain displayed in (a). (c) <321> SAED pattern obtained from the Pt grain displayed in (a). (d) Bright field scanning transmission electron microscopy (STEM) image and corresponding chemical EDS maps obtained from an interface between a BF-BT-0.13BLN grain and a Pt grain (electrode). 

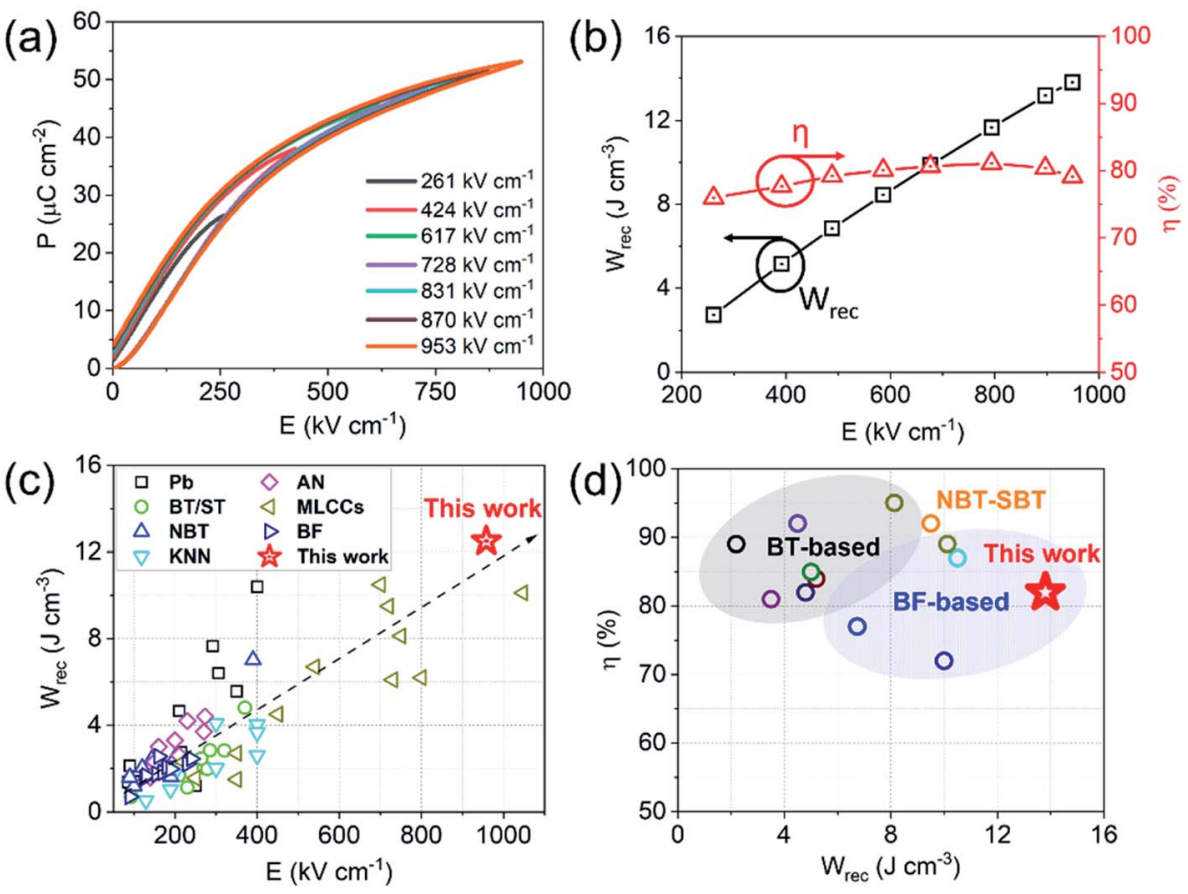

Fig. 6 (a) Room temperature (RT) unipolar P-E loops and (b) calculated energy storage properties for BF-BT-0.13BLN multilayers. (c) Comparison of $W_{\text {rec }} v s$. electric field for different lead/lead-free bulk ceramics and multilayers. ${ }^{24-56,79-99}$ (d) Comparison of $W_{\text {rec }} v s$. $\eta$ for lead-free multilayers. ${ }^{31,33-35,43,51,56,99,100}$

the Pt and the ceramic. The role of the amorphous layer is not detrimental to energy storage properties and may have a positive effect on breakdown strength through moderating field concentrations at the electrode/dielectric interface and on polarization through a space-charge mechanism. According to EDS elemental maps presented in Fig. 5d, the amorphous layer is rich in $\mathrm{Ba}$, $\mathrm{Ti}$ and $\mathrm{Fe}$ but deficient in $\mathrm{Bi}$. Bi however, is present at the surface of the Pt. Similar amorphous layers have been reported in BT-based MLCCs and their formation attributed to binder (carbon-related) burnout during the sintering process. ${ }^{34}$ Potentially this layer can be suppressed by slower or longer binder burnout stages during sintering of the devices.

We conclude that $\mathrm{Bi}$ is reduced at the $\mathrm{Pt} /$ dielectric interface by residual carbon from the binder. The reduction of $\mathrm{Bi}$ is enhanced by the formation of an alloy with the Pt, driven by the increase in entropy (reduction in free energy) through mixing. The unipolar P-E loops and energy storage properties of BF-BT-0.13BLN multilayers, are shown in Fig. 6a and b. $P_{\max } \sim 52 \mu \mathrm{C} \mathrm{cm}^{-2}$ and $P_{\mathrm{r}} \sim 4 \mu \mathrm{C} \mathrm{cm} \mathrm{cm}^{-2}$, are obtained for multilayers at $953 \mathrm{kV} \mathrm{cm}^{-1}$. The energy storage properties of multilayers are significantly enhanced with respect to monolithic ceramics, yielding a record-high $W_{\text {rec }}=13.8 \mathrm{~J}$ $\mathrm{cm}^{-3}$ with $\eta=81 \%$ at $953 \mathrm{kV} \mathrm{cm}^{-1}$; the highest value to date for lead/lead-free ceramics and multilayers (Fig. 6c,d and Table S3, ESI $\dagger$ ), fabricated using a scalable powder based technology.

The unipolar P-E loops and energy storage properties $\left(W_{\text {rec }}\right.$ and $\eta$ ), obtained from 25 to $100{ }^{\circ} \mathrm{C}$, from 0.01 to $100 \mathrm{~Hz}$ and cycled up to $10^{4}$ times at $400 \mathrm{kV} \mathrm{cm}^{-1}$ are shown in Fig. 7 . $W_{\text {rec }}$ is temperature stable $(<10 \%)$ from 25 to $100{ }^{\circ} \mathrm{C}$, with little variation $(<5 \%)$ as a function of frequency from 0.01 to $100 \mathrm{~Hz}$ and cyclic poling up to $10^{4}$ times.

There are many factors which influence the excellent properties of these materials. The high value of $W_{\text {rec }}$ is a direct consequence of being able to apply a large electric field without breakdown to a material whose crystal chemistry is designed to house highly polarisable ions within a matrix of dissimilar sized $\mathrm{ABO}_{3}$ perovskite unit cells (enhanced local polarisability). ${ }^{59}$ Temperature stability is still limited mainly by the conductivity mechanisms which become active under high electric field. In BF-BT based ceramics, $V_{\mathrm{O}}$ diffusion is facilitated above $100{ }^{\circ} \mathrm{C}$ at high electric field and creates loss, widening the unipolar loop and reducing efficiency. Nonetheless, in comparison to polymer-based capacitors with similar energy densities, the materials show promise for high-temperature applications. Our multilayers exhibit negligible degradation after $10^{4}$ cycles of the unipolar P-E loops, possibly due to the absence of significant strain $(S<$ $0.03 \%$ ) at $400 \mathrm{kV} \mathrm{cm}^{-1}$. Excellent fatigue properties are often associated with relaxor-like compositions, particular ones whose permittivity maximum is suppressed through doping with a third end member. ${ }^{32,33,51}$ The low strain prevents large cyclic changes in dimensions and eventual micro-cracking. Lead-based bulk ceramic or ceramic films, often exhibit excellent energy storage performance but are accompanied by high electric field-induced strain $(S>0.4 \%)$, leading to thermo- and mechanical-related failure due to microcracking. ${ }^{101-103}$ 
(a)

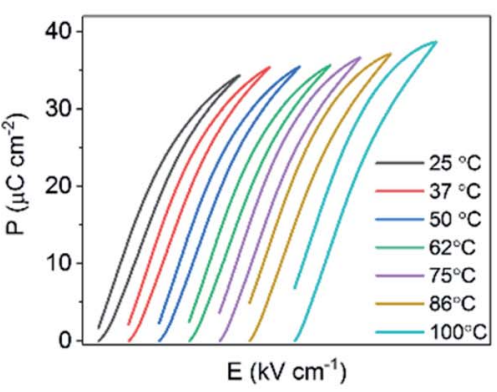

(c)

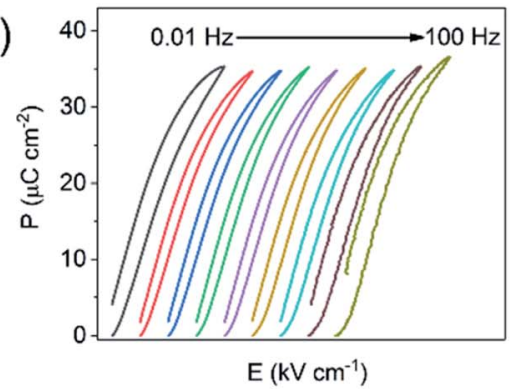

(e)

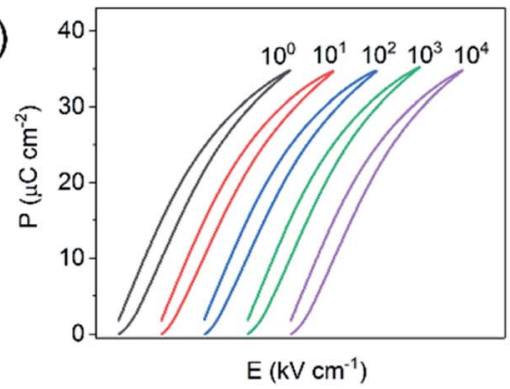

(b)

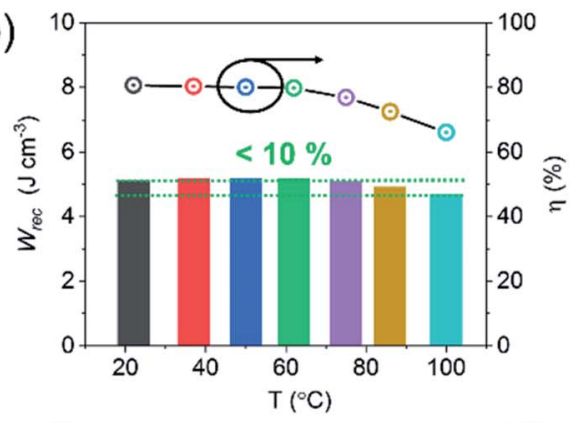

(d)

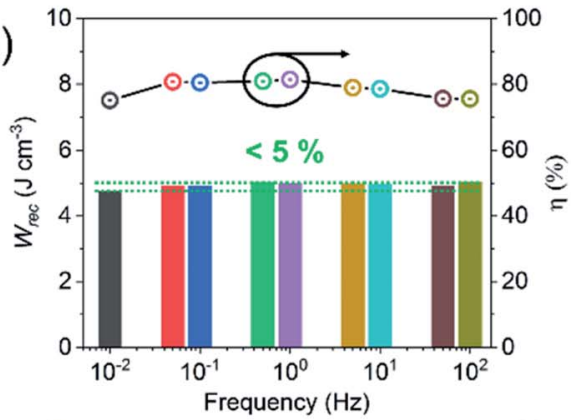

(f)

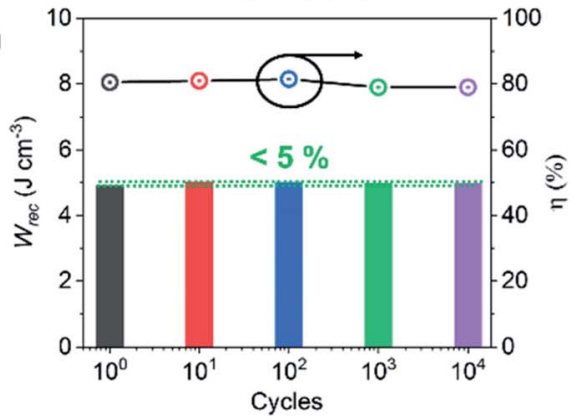

Fig. 7 (a) Unipolar P-E loops at temperature range from 25 to $100{ }^{\circ} \mathrm{C}$ and (b) calculated energy storage properties at $400 \mathrm{kV} \mathrm{cm}^{-1}$; (c) unipolar $\mathrm{P}-\mathrm{E}$ loops at frequency range from 0.01 to $100 \mathrm{~Hz}$ and (d) calculated energy storage properties at $400 \mathrm{kV} \mathrm{cm}^{-1}$; (e) unipolar P-E loops cycled up to $10^{4}$ times and $(f)$ calculated energy storage properties for BF-BT-0.13BLN multilayers at $400 \mathrm{kV} \mathrm{cm}^{-1}$.

Multilayers with $x=0.13$ therefore, have the potential to replace the lead-based systems for pulsed power applications. Furthermore, BT-BF-0.13BLN multilayers are rare-earth (RE)free with low sintering temperature $\sim 890{ }^{\circ} \mathrm{C}$, providing an opportunity for sustainable manufacturing and indicating potential compatibility with $\mathrm{Ag}-10 \% \mathrm{Pd}$ internal electrodes.

\section{Conclusions}

In summary, novel $(0.7-x) \mathrm{BiFeO}_{3}-0.30 \mathrm{BaTiO}_{3}-x \mathrm{Bi}\left(\mathrm{Li}_{0.5} \mathrm{Nb}_{0.5}\right)$ $\mathrm{O}_{3}$ (BF-BT- $x$ BLN) ceramics and multilayers are successfully fabricated using solid-state reaction and tape-casting, respectively. $W_{\text {rec }} \sim 13.8 \mathrm{~J} \mathrm{~cm}^{-3}$ was recorded $\sim 950 \mathrm{kV} \mathrm{cm}^{-1}$ for BF-BT0.13BLN multilayers with $\sim 8 \mu \mathrm{m}$ thick dielectric layers. Under electric field of $400 \mathrm{kV} \mathrm{cm}^{-1}$, multilayers are temperature stable $(<10 \%)$ from RT to $100{ }^{\circ} \mathrm{C}$, frequency independent $(<5 \%)$ from 0.01 to $100 \mathrm{~Hz}$ and fatigue-resistant $(<5 \%)$ up to $10^{4}$ cycles of the unipolar P-E loops. Additionally, BT-BF-0.13BLN multilayers are RE-free with a low sintering temperature $\left(890^{\circ} \mathrm{C}\right)$ and are therefore considered promising lead-free candidates for energy storage applications.

\section{Materials and methods}

\section{Ceramics and MLCCs fabrication}

BF-BT based ceramics within the ternary solid solution, $(0.7-$

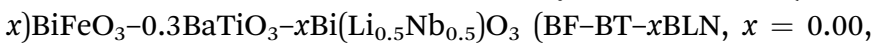
$0.02,0.5,0.08,0.10,0.13,0.15)$ were synthesized using conventional solid-state reaction. ${ }^{51,52}$ Ceramic multilayers were fabricated using an MTI MSK-AFA-II tape caster with a single doctor blade on a single-side silicon-coated mylar film. Pt electrodes were printed onto the tape using a DEK 247 screen printer, followed by tape stacking and hot-pressing $\left(70^{\circ} \mathrm{C}\right.$ for 10 min). Multilayers were sintered at $890{ }^{\circ} \mathrm{C}$ for $2 \mathrm{~h}$ with an intermediate binder burnout step $\left(180^{\circ} \mathrm{C}\right.$ for $4 \mathrm{~h}$ and $300{ }^{\circ} \mathrm{C}$ for $2 \mathrm{~h}$ ). Finally, Au terminal electrodes were painted on the side of the multilayers and fired $2 \mathrm{~h}$ at $850{ }^{\circ} \mathrm{C} .{ }^{56}$

\section{Microstructural characterization}

Densities of sintered ceramics were determined by the Archimedes method and achieved $>95 \%$ of the theoretical density. The phase assemblage, structure and microstructure at RT were evaluated by XRD (Bruker D2 Phaser) and SEM (FEI Inspect F50) 
equipped with BSE and EDS detectors). For SEM, sintered samples were firstly ground then polished to a mirror finish using wet abrasive paper and diamond paste (MetPrep Ltd.). Specimens for TEM were prepared by mechanical grinding, polishing and then ion milling. Ion milling was performed using a Gatan precision ion polishing system (PIPS II) at liquid nitrogen temperature to minimize surface damage of the specimens. A JEOL-F200 microscope was used for HRTEM and STEM imaging as well as EDS analysis.

\section{Electrical characterization}

For electrical measurements, Au was sputtered on the top and bottom surfaces of ceramic pellets. Ferroelectric P-E loops were measured using an aixACCT TF $2000 \mathrm{E}$ system from RT to $125^{\circ} \mathrm{C}$ using a $1 \mathrm{~Hz}$ triangular signal. The dielectric properties as a function of temperature were evaluated from RT to $600{ }^{\circ} \mathrm{C}$ at 1, 10, 100 and $250 \mathrm{kHz}$ using an LCR meter (Agilent 4184A). Impedance data were collected using an Agilent E4980A impedance AC analyser from RT to $400{ }^{\circ} \mathrm{C}$ at intervals of $25{ }^{\circ} \mathrm{C}$. Impedance data was normalised by a geometric factor (thickness/surface area) and then analysed using a ZView software (Scribner Associates, Inc., Southern Pines, NC). Details of how resistance and capacitance values were extracted for the different electro-active regions from combined $\mathrm{Z}^{\prime \prime}$ and $\mathbf{M}^{\prime \prime}$ spectroscopic plots are given in previous publications. ${ }^{\mathbf{6 8 , 1 0 4 , 1 0 5}}$

\section{Conflicts of interest}

The authors declare no competing financial interest.

\section{Acknowledgements}

This work was supported by the Engineering and Physical Sciences Research Council (EP/L017563/1 and EP/N010493/1), Henry Royce Institute for Advanced Materials, funded through EPSRC grants EP/R00661X/1, EP/S019367/1, EP/P02470X/1 and EP/P025285/1 and National Natural Science Foundation of China (51602060 and 51402005). The authors are grateful for support provided by Functional Materials and Devices group from University of Sheffield and would like to thank Zhongming Fan from Iowa State University for assistance with TEM work.

\section{References}

1 B. Chu, X. Zhou, K. Ren, B. Neese, M. Lin, Q. Wang, F. Bauer and Q. M. Zhang, Science, 2006, 313, 334-336.

2 Q. Li, L. Chen, M. R. Gadinski, S. Zhang, G. Zhang, H. Li, A. Haque, L. Chen, T. Jackson, Q. Wang and E. Iagodkine, Nature, 2015, 523, 576-579.

3 L. Zhao, Q. Liu, J. Gao, S. Zhang and J. F. Li, Adv. Mater., 2017, 29, 1701824-1701827.

4 G. R. Love, J. Am. Ceram. Soc., 1990, 73, 323-328.

5 K. Seongtae, W. Hackenberger, E. Alberta, E. Furman and M. Lanagan, IEEE Electrical Insulation Magazine, 2011, 27, 43-55.
6 H. Sun, W. Wang, H. Jiao, S. Wang, H. Zhu and S. Jiao, Chem. Commun., 2015, 51, 11892-11895.

7 X. Zhang, S. Jiao, J. Tu, W.-L. Song, X. Xiao, S. Li, M. Wang, H. Lei, D. Tian, H. Chen and D. Fang, Energy Environ. Sci., 2019, 12, 1918-1927.

8 S. Wang, S. Jiao, J. Wang, H.-S. Chen, D. Tian, H. Lei and D.-N. Fang, ACS Nano, 2017, 11, 467-477.

9 Z. Yu, S. Jiao, S. Li, X. Chen, W.-L. Song, T. Teng, J. Tu, H.-S. Chen, G. Zhang and D.-N. Fang, Adv. Funct. Mater., 2019, 29, 1806799.

10 Y. Song, S. Jiao, J. Tu, J. Wang, Y. Liu, H. Jiao, X. Mao, Z. Guo and D. J. Fray, J. Mater. Chem. A, 2017, 5, 1282-1291.

11 H. Jiao, C. Wang, J. Wang, J. Tu, J. Zhu and S. Jiao, Chem. Commun., 2017, 53, 2331-2334.

12 S. Wang, Z. Yu, J. Tu, J. Wang, D. Tian, Y. Liu and S. Jiao, Adv. Energy Mater., 2016, 6, 1600137.

13 W. Wang, B. Jiang, W. Xiong, H. Sun, Z. Lin, L. Hu, J. Tu, J. Hou, H. Zhu and S. Jiao, Sci. Rep., 2013, 3, 3383.

14 W. B. Hu, Y. Liu, R. L. Withers, T. J. Frankcombe, L. Noren, A. Snashall, M. Kitchin, P. Smith, B. Gong, H. Chen, J. Schiemer, F. Brink and J. Wong-Leung, Nat. Mater., 2013, 12, 821-826.

15 Q. Li, G. Zhang, F. Liu, K. Han, M. R. Gadinski, C. Xiong and Q. Wang, Energy Environ. Sci., 2015, 8, 922-931.

16 C. Liu, F. Li, L. P. Ma and H. M. Cheng, Adv. Mater., 2010, 22, E28-E62.

17 I. Hadjipaschalis, A. Poullikkas and V. Efthimiou, Renewable Sustainable Energy Rev., 2009, 13, 1513-1522.

18 H. Chen, T. N. Cong, W. Yang, C. Tan, Y. Li and Y. Ding, Prog. Nat. Sci., 2009, 19, 291-312.

19 Z. Fan, C. Zhou, X. Ren and X. Tan, Appl. Phys. Lett., 2017, 111, 252902.

20 Z. Fan, J. Koruza, J. Rodel and X. Tan, Acta Mater., 2018, 151, 253-259.

21 Z. Fan and X. Tan, J. Eur. Ceram. Soc., 2018, 38, 3472-3477.

22 Z. Fan, L. Zhou, T. H. Kim, J. Zhang, S. T. Zhang and X. Tan, Phys. Rev. Mater., 2019, 3, 024402.

23 H. Wang, Y. Liu, T. Yang and S. Zhang, Adv. Funct. Mater., 2019, 29, 1807321.

24 L. Zhao, Q. Liu, S. Zhang and J.-F. Li, J. Mater. Chem. A, 2016, 4, 8380 .

25 Y. Tian, L. Jin, H. Zhang, Z. Xu, X. Wei, E. D. Politova, S. Y. Stefanovich, N. V. Tarakina, I. Abrahams and H. Yan, J. Mater. Chem. A, 2016, 4, 17279.

26 L. Zhao, J. Gao, Q. Liu, S. Zhang and J.-F. Li, ACS Appl. Mater. Interfaces, 2018, 10, 819-826.

27 L. Zhao, Q. Liu, J. Gao, S. Zhang and J.-F. Li, Adv. Mater., 2017, 29, 1701824.

28 Y. Tian, L. Jin, H. Zhang, Z. Xu, X. Wei, G. Viola, I. Abrahams and H. Yan, J. Mater. Chem. A, 2017, 5, 17525.

29 Q. Yuan, G. Li, F.-Z. Yao, S.-D. Cheng, Y. Wang, R. Ma, S.-B. Mi, M. Gu, K. Wang, J.-F. Li and H. Wang, Nano Energy, 2018, 52, 203-210.

30 Q. Fan, M. Liu, C. Ma, L. Wang, S. Ren, L. Lu, X. Lou and C.-L. Jia, Nano Energy, 2018, 51, 539-545.

31 W.-B. Li, D. Zhou, R. Xu, L.-X. Pang and I. M. Reaney, ACS Appl. Energy Mater., 2018, 1, 5016-5023. 
32 W.-B. Li, D. Zhou, L.-X. Pang, R. Xu and H.-H. Guo, J. Mater. Chem. A, 2017, 5, 19607-19612.

33 W. Li, D. Zhou, R. Xu, D.-W. Wang, J. Su, L.-X. Pang, W. Liu and G.-H. Chen, ACS Appl. Energy Mater., 2019, 2, 54995506.

34 Z. Cai, C. Zhu, H. Wang, P. Zhao, L. Chen, L. Li and X. Wang, J. Mater. Chem. A, 2019, 7, 14575.

35 P. Zhao, H. Wang, L. Wu, L. Chen, Z. Cai, L. Li and X. Wang, Adv. Energy Mater., 2019, 9, 1803048.

36 Z. Shen, X. Wang, B. Luo and L. Li, J. Mater. Chem. A, 2015, 3, 18146.

37 H. Qi and R. Zuo, J. Mater. Chem. A, 2019, 7, 3971.

38 Y. Pu, L. Zhang, Y. Cui and M. Chen, ACS Sustainable Chem. Eng., 2018, 6, 6102-6109.

39 J. Wu, A. Mahajan, L. Riekehr, H. Zhang, B. Yang, N. Meng, Z. Zhang and H. Yan, Nano Energy, 2018, 50, 723-732.

40 H. Yang, F. Yan, Y. Lin and T. Wang, ACS Sustainable Chem. Eng., 2017, 5, 10215-10222.

41 Z. Pan, D. Hu, Y. Zhang, J. Liu, B. Shen and J. Zhai, J. Mater. Chem. C, 2019, 7, 4072-4078.

42 C. Yang, P. Lv, J. Qian, Y. Han, J. Ouyang, X. Lin, S. Huang and Z. Cheng, Adv. Energy Mater., 2019, 9, 1803949.

43 J. Li, F. Li, Z. Xu and S. Zhang, Adv. Mater., 2018, 30, 1802155.

44 Y. Zhang, W. Li, S. Xu, Z. Wang, Y. Zhao, J. Li and W. Fei, J. Mater. Chem. A, 2018, 6, 24550-24559.

45 F. Li, J. Zhai, B. Shen, X. Liu and H. Zeng, Mater. Res. Lett., 2018, 6, 345-352.

46 B. Qu, H. Du, Z. Yang, Q. Liu and T. Liu, RSC Adv., 2016, 6, 34381.

47 Z. Yang, H. Du, S. Qu, Y. Hou, H. Ma, J. Wang, J. Wang, X. Wei and Z. Xu, J. Mater. Chem. A, 2016, 4, 13778.

48 T. Shao, H. Du, H. Ma, S. Qu, J. Wang, J. Wang, X. Wei and Z. Xu, J. Mater. Chem. A, 2017, 5, 554.

49 B. Qu, H. Du, Z. Yang and Q. Liu, J. Am. Ceram. Soc., 2017, 100, 1517-1526.

50 D. Wang, Z. Fan, W. Li, D. Zhou, A. Feteira, G. Wang, S. Murakami, S. Sun, Q. Zhao, X. Tan and I. M. Reaney, ACS Appl. Energy Mater., 2018, 1, 4403-4412.

51 D. Wang, Z. Fan, D. Zhou, A. Khesro, S. Murakami, A. Feteira, Q. Zhao, X. Tan and I. M. Reaney, J. Mater. Chem. A, 2018, 6, 4133.

52 D. Zheng, R. Zuo, D. Zhang and Y. Li, J. Am. Ceram. Soc., 2015, 98, 2692-2695.

53 D. Zheng and R. Zuo, J. Eur. Ceram. Soc., 2017, 37, 413-418. 54 N. Liu, R. Liang, X. Zhao, C. Xu, Z. Zhou and X. Dong, J. Am. Ceram. Soc., 2018, 101, 3259-3265.

55 D. Wang, G. Wang, S. Murakami, Z. Fan, A. Feteira, D. Zhou, S. Sun, Q. Zhao and I. M. Reaney, J. Adv. Dielectr., 2018, 8, 1830004.

56 G. Wang, J. Li, X. Zhang, Z. Fan, F. Yang, A. Feteira, D. Zhou, D. C. Sinclair, T. Ma, X. Tan, D. Wang and I. M. Reaney, Energy Environ. Sci., 2019, 12, 582.

57 M. H. Lee, D. J. Kim, J. S. Park, S. W. Kim, T. K Song, M.-H. Kim, W.-J. Kim, D. Do and I.-K. Jeong, Adv. Mater., 2015, 27, 6976.
58 G. H. Ryu, A. Hussain, M. H. Lee, R. A. Malik, T.-K. Song, W.-J. Kim and M.-H. Kim, J. Eur. Ceram. Soc., 2018, 38, 4414-4421.

59 I. Lewin, W. J. Laws, D. Wang and I. M. Reaney, Appl. Phys. Lett., 2017, 111, 212902.

60 P. Fiorenza, R. L. Nigro, P. Delugas, V. Raineri, A. G. Mould and D. C. Sinclair, Appl. Phys. Lett., 2009, 95, 142904.

61 J. P. Heath, J. H. Harding, D. C. Sinclair and J. S. Dean, $A d v$. Funct. Mater., 2019, 29, 1904036.

62 J. T. S. Irvine, D. C. Sinclair and A. R. West, Adv. Mater., 1990, 2, 132-138.

63 L. Yang, X. Kong, F. Li, H. Hao, Z. Cheng, H. Liu, J.-F. Li and S. Zhang, Prog. Mater. Sci., 2019, 102, 72-108.

64 R. Gerson and T. C. Marshall, J. Appl. Phys., 1959, 30, 1650. 65 H. Pan, F. Li, Y. Liu, Q. Zhang, M. Wang, S. Lan, Y. Zheng, J. Ma, L. Gu, Y. Shen, P. Yu, S. Zhang, L.-Q. Chen, Y.-H. Lin and C.-W. Nan, Science, 2019, 365, 578-582.

66 F. Yang, M. Li, L. Li, P. Wu, E. Pradal-Velazquez and D. C. Sinclair, J. Mater. Chem. A, 2018, 6, 5243-5254.

67 M. Li, L. Li, J. Zang and D. C. Sinclair, Appl. Phys. Lett., 2015, 106, 102904.

68 L. Li, M. Li, H. Zhang, I. M. Reaney and D. C. Sinclair, J. Mater. Chem. C, 2016, 4, 5779-5786.

69 A. Khesro, D. Wang, F. Hussain, D. C. Sinclair, A. Feteira and I. M. Reaney, Appl. Phys. Lett., 2016, 109, 142907.

70 S. Murakami, D. Wang, A. Mostaed, A. Khesro, A. Feteira, D. C. Sinclair, Z. Fan, X. Tan and I. M. Reaney, J. Am. Ceram. Soc., 2018, 101, 5428-5442.

71 S. Murakami, N. T. A. F. Ahmed, D. Wang, A. Feteira, D. C. Sinclair and I. M. Reaney, J. Eur. Ceram. Soc., 2018, 38, 4220-4231.

72 R. D. Shannon, Acta Crystallogr., Sect. A: Cryst. Phys., Diffr., Theor. Gen. Crystallogr., 1976, 32, 751.

73 G. Wang, Z. Fan, S. Murakami, Z. Lu, D. A. Hall, D. C. Sinclair, A. Feteira, X. Tan, J. L. Jones, A. K. Kleppe, D. Wang and I. M. Reaney, J. Mater. Chem. A, 2019, 7, 21254-21263.

74 I. Calisir, A. K. Kleppe, A. Feteira and D. A. Hall, J. Mater. Chem. C, 2019, 7, 10218-10230.

75 I. Calisir, A. A. Amirov, A. K. Kleppe and D. A. Hall, J. Mater. Chem. A, 2018, 6, 5378-5397.

76 I. Calisir and D. A. Hall, J. Mater. Chem. C, 2018, 6, 134-146. 77 Y. Lin, D. Li, M. Zhang, S. Zhan, Y. Yang, H. Yang and Q. Yuan, ACS Appl. Mater. Interfaces, 2019, 11, 36824-36830.

78 G. Wang, Z. Lu, Z. Zhang, A. Feteira, C. C. Tang and D. A. Hall, J. Am. Ceram. Soc., 2019, 102, 7746-7754.

79 L. Zhang, S. Jiang, B. Fan and G. Zhang, J. Alloys Compd., 2015, 622, 162-165.

80 Z. Liu, X. Chen, W. Peng, C. Xu, X. Dong, F. Cao and G. Wang, Appl. Phys. Lett., 2015, 106, 262901.

81 Q. Zhang, H. Tong, J. Chen, Y. Lu, T. Yang, X. Yao and Y. He, Appl. Phys. Lett., 2016, 109, 262901.

82 R. Xu, B. Li, J. Tian, Z. Xu, Y. Feng, X. Wei, D. Huang and L. Yang, Appl. Phys. Lett., 2017, 110, 142904.

83 Q. Zhang, J. Chen, Y. Lu, T. Yang, X. Yao and Y. He, J. Am. Ceram. Soc., 2016, 99, 3853-3856. 
84 Q. Zhao, H. Lei, G. He, J. Di, D. Wang, P. Tan, H. Jin and H. M. Cao, Ceram. Int., 2016, 42, 1314-1317.

85 F. Yan, H. Yang, Y. Lin and T. Wang, Inorg. Chem., 2017, 56, 13510-13516.

86 J. Yin, X. Lv and J. Wu, Ceram. Int., 2017, 43, 13541-13546. 87 Y. Pu, M. Yao, L. Zhang and M. Chen, J. Alloys Compd., 2017, 702, 171-177.

88 H. Tao and J. Wu, J. Mater. Sci.: Mater. Electron., 2017, 28, 16199-16204.

89 H. Yang, F. Yan, Y. Lin, T. Wang, L. He and F. Wang, J. Alloys Compd., 2017, 710, 436-445.

90 H. Yang, F. Yan, Y. Lin, T. Wang, F. Wang, Y. Wang, L. Guo, W. Tai and H. Wei, J. Eur. Ceram. Soc., 2017, 37, 3303-3311.

91 H. Yang, F. Yan, Y. Lin and T. Wang, Appl. Phys. Lett., 2017, 111, 253903.

92 Q. M. Zhang, L. Wang, J. Luo, Q. Tang and J. Du, Int. J. Appl. Ceram. Technol., 2010, 7, E124-E128.

93 Y. H. Huang, Y. J. Wu, W. J. Qiu, J. Li and X. M. Chen, J. Eur. Ceram. Soc., 2015, 35, 1469-1476.

94 W. B. Li, D. Zhou and L.-X. Pang, Appl. Phys. Lett., 2017, 110, 132902-132905.

95 T. Wang, L. Jin, C. C. Li, Q. Y. Hu and X. Y. Wei, J. Am. Ceram. Soc., 2015, 98, 559-566.
96 Q. Y. Hu, L. Jin, T. Wang, C. C. Li, Z. Xing and X. Y. Wei, J. Alloys Compd., 2015, 640, 416-420.

97 Q. Xu, J. Xie, Z. C. He, L. Zhang, M. H. Cao, X. D. Huang, M. T. Lanagan, H. Hao, Z. H. Yao and H. X. Liu, J. Eur. Ceram. Soc., 2017, 37, 99-106.

98 L. Chen, Y. Li, Q. Zhang and X. Hao, Ceram. Int., 2016, 42, 12537-12542.

99 H. Ogihara, C. A. Randall and S. Trolier-McKinstry, J. Am. Ceram. Soc., 2009, 92, 1719-1724.

100 G. Wang, Z. Lu, J. Li, H. Ji, H. Yang, L. Li, S. Sun, A. Feteira, H. Yang, R. Zuo, D. Wang and I. M. Reaney, J. Eur. Ceram. Soc., 2020, 40, 1779-1783.

101 Q. Zhang, J. Chen, Y. Lu, T. Yang, X. Yao and Y. He, J. Am. Ceram. Soc., 2016, 99, 3853-3856.

102 L. Chen, N. Sun, Y. Li, Q. Zhang, L. Zhang and X. Hao, J. Am. Ceram. Soc., 2018, 101, 2313-2320.

103 M. S. Mirshekarloo, K. Yao and T. Sritharan, Appl. Phys. Lett., 2010, 97, 142902.

104 L. Li, M. Li, I. M. Reaney and D. C. Sinclair, J. Mater. Chem. C, 2017, 5, 6300-6310.

105 L. Li, M. Li and D. C. Sinclair, Appl. Phys. Lett., 2018, 112, 182907. 